International Journal of Automotive and Mechanical Engineering (IJAME)

ISSN: 2229-8649 (Print); ISSN: 2180-1606 (Online); Volume 8, pp. 1218-1225, July-December 2013

(O) Universiti Malaysia Pahang

DOI: http://dx.doi.org/10.15282/ijame.8.2013.12.0100

\title{
HYDROXYPROPYLMETHYLCELLULOSE AS A PRIMARY VISCOSIFYING AGENT IN CEMENT SLURRY AT HIGH TEMPERATURE
}

\author{
Ghulam Abbas $^{1 *}$, Sonny Irawan ${ }^{1}$, Khalil .R. Memon ${ }^{1}$, Sandeep Kumar ${ }^{1}$ and \\ Ahmed A.I. Elrayah ${ }^{1}$ \\ ${ }^{1}$ Department of Petroleum Engineering, Universiti Teknologi PETRONAS \\ 31750, Bandar Seri Iskandar, Perak Darul Ridzuan, Malaysia \\ "Email: engr_abbas27@live.com \\ Phone: +605-368-7085
}

\begin{abstract}
The use of polymer in cement slurry is necessary to retain viscosity at ambient temperature and thermal thickening properties with increasing temperature. Current polymers, polysaccharides and their derivatives are extensively studied. At high temperature these polymers do not yield thickening of viscosity, but exhibit loss of slurry and gas migration. Therefore, this study presents hydroxypropylmethylcellulose (HPMC) polymer as a viscosifying agent in cement slurry. The HPMC possesses a strong thermal thickening and solid suspension ability which means low viscosity at ambient temperature and viscosity increase with respect to temperature. Thus, a series of experiments was conducted on HPMC polymer as a viscosifying agent in cement slurry. Different concentrated solutions were prepared (i.e. 1.5 to $2.5 \mathrm{wt} \%$ ), in order to characterize their viscosity with respect to shear rate and increasing temperature up to $100^{\circ} \mathrm{C}$. Then, cement slurries were prepared with HPMC as the primary viscosifier, to determine the rheological properties at high temperatures. It was observed that HPMC polymer has increased viscosity from $90^{\circ} \mathrm{C}$ to $100^{\circ} \mathrm{C}$. The improved rheology of cement slurry, in terms of plastic viscosity and yield point at different concentrations, revealed HPMC as a capable viscosifying agent at high temperature. Moreover, increased gel strength with increasing concentration was also observed, which may cause a higher pumping rate on the surface. It was concluded that HPMC polymer acts as a viscosifying agent at high temperature. HPMC-based slurries showed high rheology (plastic viscosity and yield point) with HPMC polymer. Thus, the use of this additional additive should be considered in the design of appropriate cement slurry.
\end{abstract}

Keywords: Cement slurry; gel strength; hydroxypropylmethylcellulose (HPMC); temperature; viscosity.

\section{INTRODUCTION}

Cement has been used in drilling operations to restrict fluid movement between zones, protect casing from corrosion and closing abandoned portions of wells (Roshan \& Asef, 2010). Additives and polymers have been used in oil well cementing to improve the properties of cement slurry. Polysaccharides and their derivatives, including hydroxyethylcellulose (HEC), carboxymethyl hydroxyethylcellulose (CMHEC), guar, hydroxypropylguar, stach, xanthan, welan gum, scleroglucan, diutan and carrageenan polymers, are being used as viscosifying agents and multifunctional additives in cement slurry (Navarrete, Seheult, \& Coffey, 2001, Navarrete \& Shah, 2001). Cementing mid to high temperature wells poses a challenge for these types of polymer. Temperature 
increase at the bottom hole condition is usually observed with increasing well depth. Polysaccharides and their derivatives are unstable at high temperature. Polysaccharidesbased cement slurries steadily lose their viscosity and strength with increasing temperature, which creates the problems of fluid loss through the slurry, decrease in compressive strength, gas migration and ultimately causes the well to be abandoned. A high concentration of polymer is being used to maintain the viscosity of the cement slurry at elevated temperature. Increasing the concentration of polymers in cement slurry causes viscosification of the slurry at the surface condition, which then requires high pumping pressure (Reddy, Patil, \& Patil, 2011). Additional pumping pressure may cause serious problems of formation damage and loss of circulation. These types of polymer-based cement slurry create problems due to the high concentration of polymer. Therefore, it is necessary to use a type of polymer that can retain the viscosity of the cement slurry at ambient temperature and have thermal thickening properties with increasing temperature.

Polysaccharides polymers such as HEC have been synthesized and modified with organic carbonate to retain the viscosity of the polymer solution at ambient temperature and increase the viscosity at high temperature (Reddy, 2011). The usage of chemicals in cement slurry affects the properties of other additives and increases the cost of the cementing operation. On other hand, hydroxypropylmethylcellulose (HPMC) is a cellulose-type polymer that acts as a self-active viscosifier at gelation temperature and is sustainable at high temperature. HPMC polymer, as a self-active viscosifier, has no need of any other chemical to increase the viscosity, which is the advantage of this polymer over other cellulose-type polymers. Previously, HPMC polymer was used in cement for construction to increase the strength and mechanical properties of the cement $(\mathrm{Fu}, 1996)$. Recently, HPMC polymer used in EOR applications for profile modification was stable at $110^{\circ} \mathrm{C}$ and was used as a permeability reducing agent (He et al., 2012). The present study demonstrates the ability of HPMC polymer as a viscosifying agent in cement slurry at high temperature. The properties of HPMC polymer in terms of viscosity and gel strength at different concentrations and temperatures have been determined. Further rheology of polymer-based cement slurry is also discussed in this paper.

\section{THEORETICAL BACKGROUND OF HPMC POLYMER}

HPMC is a water-soluble polymer derived from cellulose ether and behaves as a thickener, film former, water retention agent, suspension aid, surfactant and good (reasonable) gel strength agent at high temperature (Abbas et al., 2013). These characteristics make it suitable for use in a wide range of applications and diverse industries, including food and pharmaceuticals, and in many types based on ether substitution, particle size, viscosity and other parameters. The formulated structure of HPMC with a degree of substitution of 1.5 is illustrated in Figure 1. In civil engineering, HPMC has been used in cement for its multifunctional properties. As a result, articles about the effect of HPMC on cement have been published. Various properties such as compressive strength, heat of hydration, improved rheology of cement, and the thixotropic behavior of the HPMC were examined. 


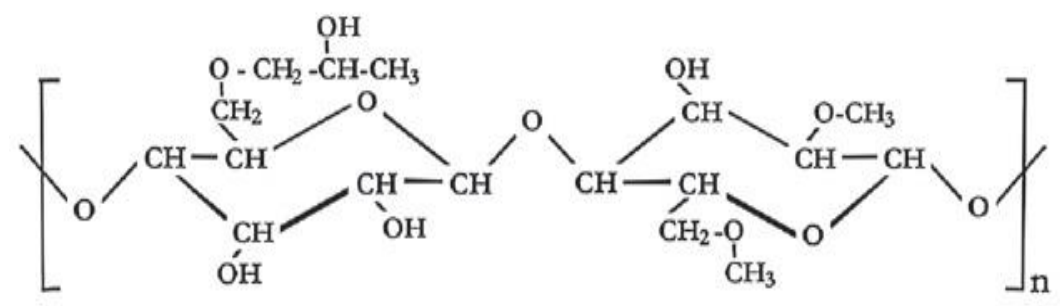

Figure 1. HPMC structure with degree of substitution of 1.5 (Ou, Ma, \& Jian, 2012).

\section{METHODOLOGY}

\section{Preparation of HPMC Polymer Solution}

HPMC polymer is in the form of white fine powder. Commercial HPMC polymer was used for the experiments. Three different concentrations, 1.5, 2 and $2.5 \mathrm{wt} \%$ of HPMC polymer solution were prepared with distilled water to determine the properties of HPMC at different temperatures.

\section{Gelation Temperature and Gel Strength Measurement}

The gelation temperature and gel strength of polymer solutions were determined by using tube inversion (Takeuchi et al., 2003) and the breakthrough vacuum method. 15 $\mathrm{ml}$ of measured solution was injected into a tube and kept in a constant temperature bath for 15 to 20 minutes and then inverted to determine the gelation temperature. For gel strength, the tube of the breakthrough vacuum was inserted into the gel to obtain the gel strength value.

\section{Viscosity of HPMC polymer}

A high pressure high temperature viscometer (OFIT 1100 model) was used to determine the viscosity of the HPMC polymer at different temperatures. Using $42 \mathrm{ml}(1.5 \mathrm{wt} \%$, $2 \mathrm{wt} \%, 2.5 \mathrm{wt} \%$ ) of each solution, the viscosity was determined by changing the shear rate between 1 and $1000 \mathrm{~s}^{-1}$. To examine the viscosity of the HPMC solution at ambient temperature and high temperature, the viscosity of each sample was determined at various temperatures ranging from 30 to $100^{\circ} \mathrm{C}$.

\section{Preparation of Cement Slurry}

The density of 16.5 pounds per gallon (ppg) was designed to evaluate the effect of the HPMC polymer on cement slurry at high temperature. Various cement slurries were prepared by changing the concentration of the HPMC polymer from 0.20 to 0.50 gallons per sack (gps) of each solution. The composition of the cement slurries contained Class $\mathrm{G}$ cement, HPMC polymer and water. The cement, water and solution of HPMC polymer were mixed at constant high speeds of $4000 \mathrm{rpm}$ and 12,000 rpm according to API RP10-2B procedure (API Edition, 2009). 


\section{Rheology of Cement Slurry}

The rheological properties of the cement slurries were determined by using the HPHT viscometer. The rheology of the cement slurries was performed in terms of plastic viscosity, yield point, gel strength at 10 second and gel strength at 10 minutes according to API RP10-2B procedure. The rheology of all the slurries was determined at $90^{\circ} \mathrm{C}$.

\section{RESULTS AND DISCUSSION}

In this paper, the impact of HPMC polymer on oil well cement as a viscosifying agent was examined based on the viscosity of the polymer and the rheology of the HPMCbased cement slurry. The gelation temperature and gel strengths of 1.5, 2 and $2.5 \mathrm{wt} \%$ polymer solution were determined by using a breakthrough vacuum and tube inversion method. The gelation temperature and gel strength of all the solutions were greater than $80^{\circ} \mathrm{C}$, as shown in Table 1 . It was observed that the gelation temperature of HPMC solution decreases with increasing concentration of polymer from 1.5 to $2.5 \mathrm{wt} \%$, but at the same time the gel strength of the solution increased with increasing concentration. The gelation temperature of the solutions was greater than $80^{\circ} \mathrm{C}$. The gelation temperature results show that above $80^{\circ} \mathrm{C}$ the solution of HPMC polymer will increase the viscosity. On the basis of the gelation temperature, the viscosity of the solutions was determined at various temperatures ranging from 30 to $100^{\circ} \mathrm{C}$. The viscosity of $1.5 \mathrm{wt} \%$ solution at $30^{\circ} \mathrm{C}$ shows the maximum viscosity of the HPMC polymer. The viscosity profile at various temperatures $\left(30\right.$ to $\left.100^{\circ} \mathrm{C}\right)$ is shown in Figure 2 .

Table 1. Gelation temperature and gel strength of HPMC polymer.

\begin{tabular}{|c|c|c|c|}
\hline $\begin{array}{l}\text { Concentration of } \\
\text { HPMC / wt \% }\end{array}$ & Gelation & temperature $/{ }^{\circ} \mathrm{C}$ & $\begin{array}{c}\text { Gel strength } \\
\mathrm{M} \mathrm{Pa}\end{array}$ \\
\hline 1.5 & 84 & & 0.014 \\
\hline 2 & 83 & & 0.017 \\
\hline 2.5 & 81 & & 0.020 \\
\hline
\end{tabular}

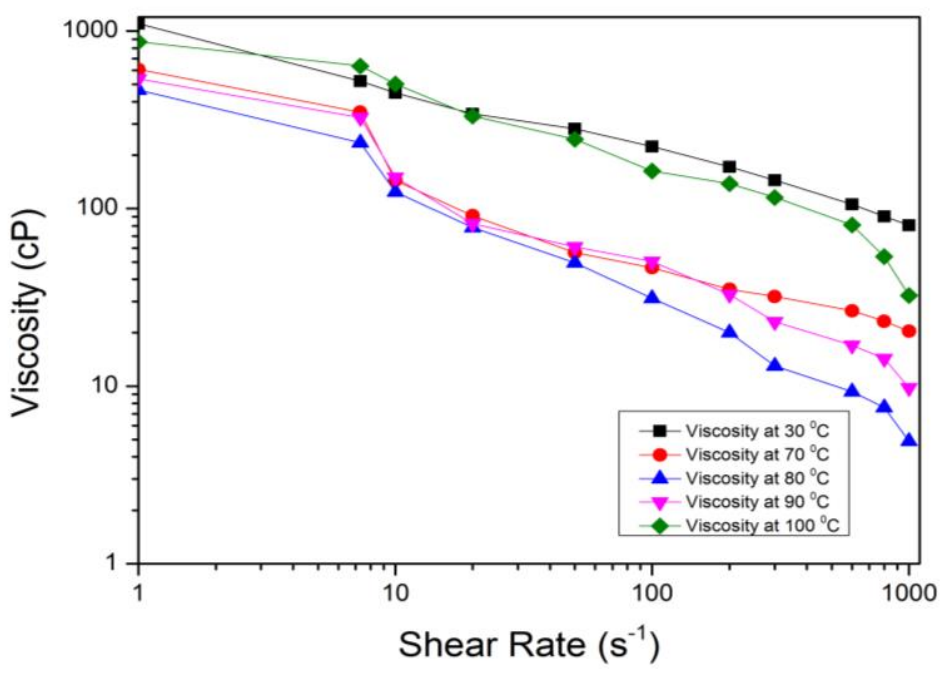

Figure 2. Shear rate vs viscosity of $1.5 \mathrm{wt} \%$ HPMC at different temperatures. 
The viscosity of the HPMC polymer was determined in terms of shear rate. Figure 2 shows the trend of viscosity at different shear rates and temperatures of $30^{\circ} \mathrm{C}$, $70^{\circ} \mathrm{C}, 80^{\circ} \mathrm{C}, 90^{\circ} \mathrm{C}$ and $100^{\circ} \mathrm{C}$. At $30^{\circ} \mathrm{C}$ the solution of polymer that contained $1.5 \mathrm{wt} \%$ of HPMC showed the maximum viscosity at $1 \mathrm{~s}^{-1}$ shear rate, and with increasing the shear rate from 1 to $1000 \mathrm{~s}^{-1}$, the viscosity decreased from 1100 to 80.4 centipoise (cP). The HPMC polymer showed shear thinning behavior with increasing shear rate. The high shear rate disturbs the chemical bond structure of the HPMC polymer. The molecules of the HPMC polymer separate and decrease the viscosity of the solution. The HPMC polymer shows thinning behavior with increasing temperature. The viscosity of the HPMC polymer decreased with increasing temperature. The HPMC polymer showed reduced viscosity when increasing the temperature from 30 to $80^{\circ} \mathrm{C}$, as shown in Figure 2. The reduction in viscosity was due to the reduction in molecular weight and structure of the HPMC polymer. On the other hand, the viscosity of the solution increases at $90^{\circ} \mathrm{C}$, as shown in Figure 2. The viscosity of the HPMC polymer at $90^{\circ} \mathrm{C}$ is greater than the viscosity of the solution at 70 and $80^{\circ} \mathrm{C}$. It is a property of HPMC polymer that above the gelation temperature it will increase viscosity. The viscosity of the solution increases from 465 to $537 \mathrm{cP}$ at a low shear rate and 4.9 to 9.8 $\mathrm{cP}$ at a high shear rate. Further, at $100^{\circ} \mathrm{C}$ the viscosity of the solution is enhanced to $869.4 \mathrm{cP}$ at $1 \mathrm{~s}^{-1}$ shear rate and $32.4 \mathrm{cP}$ at $1000 \mathrm{~s}^{-1}$ shear rate. Increasing viscosity proves that at high temperatures greater than the gelation temperature the HPMC polymer acts as a viscosifying agent. This unique property of increasing the viscosity is only observed in HPMC polymer and not in other types of cellulose. Similarly, the same effect of increasing the viscosity was also observed in the $2 \mathrm{wt} \%$ concentration of HPMC polymer solution, as shown in Figure 3.

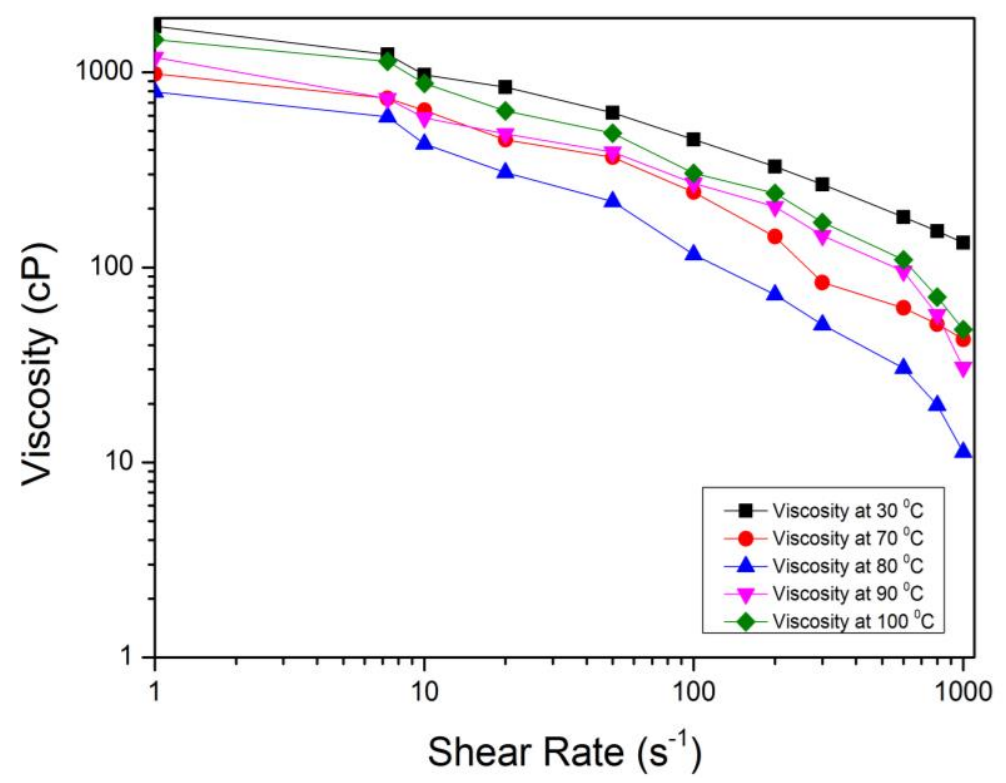

Figure 3. Shear rate vs viscosity of $2 \mathrm{wt} \%$ solution at different temperatures.

Figure 3 shows the same trend of viscosity increasing at temperatures from 30 to $100^{\circ} \mathrm{C}$. But the viscosity of $2 \mathrm{wt} \%$ HPMC solutions is greater than $1.5 \mathrm{wt} \%$ polymer solutions at all shear rates. Here the increase in viscosity of the HPMC polymer was due to the increase in the molecular weight of the solution. Further, the effect of $2.5 \mathrm{wt} \%$ HPMC polymer is shown in Figure 4. It was observed that the viscosity was increasing 
with increasing concentration. The high concentration of polymer increases the molecular weight of the solution and this increases the viscosity. Similar to the other solutions, the $2.5 \mathrm{wt} \%$ HPMC solution enhanced viscosity above a gelation temperature of $80^{\circ} \mathrm{C}$.

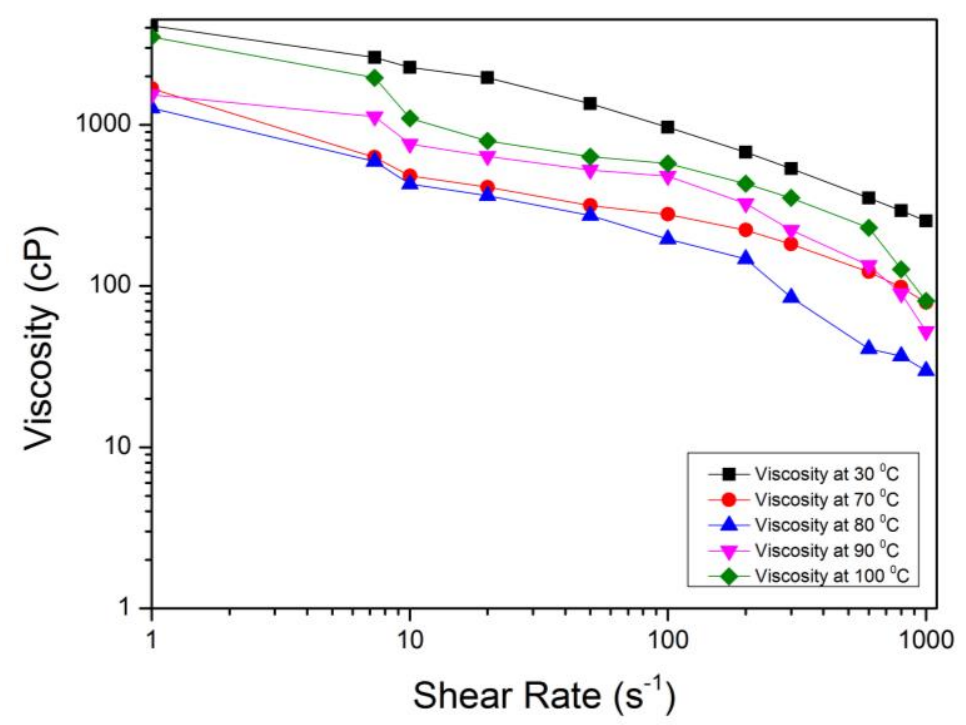

Figure 4. Shear rate vs viscosity of $2.5 \mathrm{wt} \%$ solution at different temperatures.

The concentration of HPMC polymer also affects the viscosity of the solutions. Comparison of all the HPMC solutions (Figures 2 to 4 ) shows that as the concentration of the polymer increases from 1.5 to 2 and $2.5 \mathrm{wt} \%$, the viscosity of the polymer also increases at all temperatures. The increase in the viscosity of HPMC solution at gelation temperature is due to the hydrophobic interaction between the molecules of the methoxyl group. With increasing temperature, the HPMC solution loses the water of hydration, which becomes the cause of the reduction of viscosity. But at the gelation temperature, sufficient dehydration of polymer occurs to cause the polymer-to-polymer association and the solution begins to increase in viscosity ( $\mathrm{He}$ et al., 2012). The rheology of the HPMC-based cement slurry was determined for each solution at $90^{\circ} \mathrm{C}$ using the HPHT viscometer. The rheology of all the HPMC solutions in terms of plastic viscosity, yield point and gel strength is given in Table 2 .

The rheology of the cement slurries increases with increasing concentrations, 1.5 to 2 and $2.5 \mathrm{wt} \%$, of HPMC solution. Slurries 1 to 8 , which contain 1.5 and $2 \mathrm{wt} \%$ of solution and have different HPMC concentrations of 0.20 to 0.50 gps, show lower rheology than slurries 9 to 12, which contain $2.5 \mathrm{wt} \%$ of HPMC. All the cement slurries having 1.5 and $2 \mathrm{wt} \%$ show improved rheology compared with the $2.5 \mathrm{wt} \%$ because these slurries have lower plastic viscosity and yield points than the other slurries, as shown in Table 2. On the other hand, the gel strength of the cement slurries is high, which could be a problem at the time of pumping at the surface condition. The gel strength and viscosity of the slurries increases with increased concentration, which was due to the water absorption on its methoxyl group (Roshan \& Asef, 2010). But the absorption of water and increase of viscosity keep the slurry stable at high temperature. To a limited extent, the $1.5 \mathrm{wt} \%$ HPMC solution improves the rheology at high temperature. But the gel strength of the cement slurry was high especially in the case of the $2.5 \mathrm{wt} \%$ solution of HPMC. The high gel strength of the cement slurry will become 
a serious problem at the time of pumping, requiring high pump pressure and becoming the cause of fracture and slurry loss when pumping (Sabins, Tinsley, \& Sutton, 1982).

Table 2. Rheology of HPMC-based cement slurry at $90^{\circ} \mathrm{C}$.

\begin{tabular}{ccccccc}
\hline $\begin{array}{l}\text { Slurry } \\
\text { no }\end{array}$ & $\begin{array}{l}\text { Conc. } \\
\text { of } \\
\text { polymer }\end{array}$ & $\begin{array}{l}\text { HPMC } \\
\text { gps }\end{array}$ & $\begin{array}{l}\text { Plastic } \\
\text { viscosity } \\
(\mathrm{cP})\end{array}$ & $\begin{array}{l}\text { Yield } \\
\text { point } \\
\left(1 \mathrm{~b} / \mathrm{ft}^{2}\right)\end{array}$ & $\begin{array}{l}\text { 10 Sec } \\
\text { gel } \\
\text { strength }\end{array}$ & $\begin{array}{l}\text { 10 minute } \\
\text { gel } \\
\text { strength }\end{array}$ \\
\hline 1 & 1.5 & 0.20 & 70 & 40 & 48 & 90 \\
2 & 1.5 & 0.30 & 76 & 50 & 53 & 94 \\
3 & 1.5 & 0.40 & 79 & 63 & 56 & 102 \\
4 & 1.5 & 0.50 & 83 & 73 & 55 & 108 \\
5 & 02 & 0.20 & 91 & 49 & 31 & 51 \\
6 & 02 & 0.30 & 93 & 51.67 & 22 & 53 \\
7 & 02 & 0.40 & 95 & 55 & 23 & 55 \\
8 & 02 & 0.50 & 99 & 56 & 25 & 69 \\
9 & 2.5 & 0.20 & 135 & 65 & 73 & 102 \\
10 & 2.5 & 0.30 & 140.64 & 72 & 77 & 110 \\
11 & 2.5 & 0.40 & 148.04 & 82 & 80 & 116 \\
12 & 2.5 & 0.50 & 150 & 86 & 83 & 119 \\
\hline
\end{tabular}

\section{CONCLUSIONS}

i) At increasing temperature from 30 to $80^{\circ} \mathrm{C}$, HPMC polymer shows thermal thinning behavior but above a gelation temperature of $90^{\circ} \mathrm{C}$ the $\mathrm{HPMC}$ polymer increases the viscosity and so acts as a viscosifying agent and is then stable at high temperature.

ii) At 1.5 and $2 \mathrm{wt} \%$ concentrations of HPMC, the cement slurries have improved rheology in terms of plastic viscosity and yield point.

iii) A high gel strength of $2.5 \mathrm{wt} \%$ concentration of HPMC polymer in cement slurry requires high pumping pressure at the surface condition. Friction reduction additives should be used in $2.5 \mathrm{wt} \%$ based cement slurries to reduce the gel strength.

iv) At high temperature, HPMC polymer shows thixotropic behavior that should be beneficial for controlling gas migration through the cement slurry.

v) HPMC polymer can be used as a multifunctional additive in cement slurry to increase compressive strength and thickening time. In further study, fluid loss, compressive strength, thickening time and static gel strength of HPMC-based cement slurries will be examined at high temperature.

\section{ACKNOWLEDGMENTS}

This research work was supported by Universiti Teknologi PETRONAS, Malaysia. The authors wish to express their sincere thanks to Yil-Long Chemical Group Limited (China) for the supply of hydroxypropylmethylcellulose polymer. 


\section{REFERENCES}

Abbas, G., Irawan, S., Kumar, S., \& Elrayah, A. A. I. (2013). Improving oil well cement slurry performance using hydroxypropylmethylcellulose polymer. Advanced Material Research, 787, 222-227.

API-RP 10B-2. 2009. Recommended practice for testing well cements. Washington, DC, 22-02.

$\mathrm{Fu}, \mathrm{X}$. (1996). Effect of methylcellulose admixture on the mechanical properties of cement. Cement and Concrete Research, 26(4), 535-538.

He, H., Wang, Y., Zhao, M., Cheng, L., \& Liu, P. (2012). Laboratory evaluation of thermoreversible gel for in-depth conformance control in steam-stimulated wells. Presented at the SPE Heavy Oil Conference.

Navarrete, R., Seheult, J., \& Coffey, M. (2001). New biopolymers for drilling, drill-in, completions, spacer, and coil-tubing fluids, part II. Presented at the SPE International Symposium on Oilfield Chemistry.

Navarrete, R. \& Shah, S. (2001). New biopolymer for coiled tubing applications. Presented at the SPE/ICOTA Coiled Tubing Roundtable.

Ou, Z., Ma, B., \& Jian, S. (2012). Influence of cellulose ethers molecular parameters on hydration kinetics of Portland cement at early ages. Construction and Building Materials, 33, 78-83.

Reddy, B., Patil, R., \& Patil, S. (2012). Chemical modification of biopolymers to design cement slurries with temperature-activated viscosification. SPE Drilling and Completion, 27 (2), 94-102.

Reddy, B. (2011).Viscosification-on-demand: chemical modification of biopolymers to control their activation by triggers in aqueous solutions. Presented at SPE International Symposium on Oilfield Chemistry.

Roshan, H. \& Asef, M. (2010). Characteristics of oil well cement slurry using CMC. SPE Drilling \& Completion Journal, 25(3), 328-335.

Sabins, F., Tinsley, J., \& Sutton, D. (1982). Transition time of cement slurries between the fluid and set states. Society of Petroleum Engineers Journal, 22(6), 875-882.

Takeuchi, M., Kageyama, S., Suzuki, H., Wada, T., Notsu, Y., \& Ishii, F. (2003). Rheological properties of reversible thermo-setting in situ gelling solutions with the methylcellulose-polyethylene glycol-citric acid ternary system. Colloid \& Polymer Science, 281(12),1178-1183. 